\title{
Fabricating of Steel/Cast Iron Composite by Casting Route
}

\author{
S.Ö. ERTÜRK ${ }^{a, b, *}$, O. ÇAKIR ${ }^{a, b}$, L.C. KUMruOGLU ${ }^{a, b}$ AND A. OzeL ${ }^{a, b}$ \\ ${ }^{a}$ Faculty of Engineering, University of Sakarya, Esentepe, 54187, Turkey \\ ${ }^{b}$ Faculty of Engineering, University of Sivas, Turkey
}

\begin{abstract}
In this study, 1.2333 cold work tool steel and cast iron (GG 25) were simultaneously melted in different furnaces to fabricate composite die mold used in sheet metal forming industry. To enhance the metallurgical bond between two components of composite part, the pouring temperature of cast iron was assessed just above the solidus temperature, then metallurgically prepared cast iron was poured on to the cast tool steel. The temperature and casting parameters were monitored and simulated. Experimental and simulation results were compared, finally the optimum parameters and casting route were revealed.
\end{abstract}

DOI: $10.12693 /$ APhysPolA.125.452

PACS: 47.11.-j, 81.20.Hy, 81.30.Fb, 81.05.Ni, 68.08.-p

\section{Introduction}

Bimetals are materials composed of two different metallic components that remain spatially distinct and allow two different metals to be combined in one die-mould while maintaining the distinct advantages offered by the constituent alloys. In the product, the two metals are usually intimately bonded in order to function in unison. The usefulness of bimetal products stems from the possibilities of combination of qualities of dissimilar metals. The two metals in the same part play different roles in the bimetallic cast part. Functionality and cost are sometimes the driving reasons for selecting the bimetal casting process. The bimetal cast parts could combine the merits of the two alloys together. The produced part could have relative low cost, light weight and strong mechanical properties as well as antiwear and anticorrosion properties all in one $[1,2]$. Bimetals are widely used in many fields as radiators, reservoirs, bearing and gaskets for motor-heads in automobile industry, as cutting tools in paper, metal, wood, textile, food industries, kitchen utensils, heat exchangers, electro contact, first wall/blanked material for reactor etc. [3-10] and [11].

The main interesting feature in the production of bimetal as cast is the behavior of interface between two metals. The interface can be formed by the contact of two liquid metals or contact of one liquid-one solid metals. There are many important factors in the casting of a bimetal. Constituent metals must be compatible in thermal expansion, specific heat, thermal conductivity, phase transformation region, and also melting temperature, wetting and reactivity to each other. All of these factors, especially wetting and reactivity, determine the quality of the bond between metals, and therefore has a great influence on the final properties of the bimetal cast [11].

The aim of this study is the production of bimetal consisting of the casting tool steel (with grade of 1.2333) and

*corresponding author; e-mail: sonerozden@hotmail.com the cast iron (with the grade of GG25) by sand mould casting technique using foam mold. Metallurgical bonding is formed under the contact of liquid cast iron and semiliquid casting tool steel. The interface is investigated since the mechanical properties of the bimetal are greatly controlled by the quality of the bonding produced by interaction between one semiliquid and one liquid metal.

\section{Experimental studies}

The chemical compositions of the cast tool steel (1.2333) and the gray cast iron (GG 25) were given in Table. Lost foam mold casting technique and alpha set resin were used for the production of the bimetal.

TABLE

The chemical composition of bimetal components.

\begin{tabular}{c|c|c|c|c|c|c|c|c}
\hline \hline Materials & $\mathrm{C}$ & $\mathrm{Si}$ & $\mathrm{Mn}$ & $\mathrm{Cr}$ & $\mathrm{Mo}$ & $\mathrm{V}$ & $\mathrm{S}$ & $\mathrm{P}$ \\
\hline 1.2333 & 0.638 & 0.45 & 0.67 & 4.3 & 0.45 & 0.225 & - & - \\
GG 25 & 3.2 & 1.8 & 0.64 & - & - & - & 0.08 & 0.2
\end{tabular}

Before molding the pattern and casting the grey iron, the filling and solidification were simulated with Nova Flow \& Solid ${ }^{\circledR}$ casting simulation package. The filling parameters and the feeder for the casting model were calculated according to these simulation results. The casting and mould materials were defined with their initial pouring temperatures. The bimetal consists of cast tool steel and grey cast iron. The cast tool steel was 1.2333 and the grey cast iron was GG25. The casting part is shown in Fig. 1 and the computer simulation studies are given in Fig. 2.

After the bimetal casting, the cast part was separated from the mold, then cut to gain samples. The bimetal disc that was cut out from binding zone of cast part and scanning electron micrographs (SEM) of the cross-section for interface zone of as cast bimetal are shown in Fig. 3. It is considered that the interface has a high bonding quality between the cast tool steel and the gray iron since any defect or discontinuities such as lack of bonding, voids, 


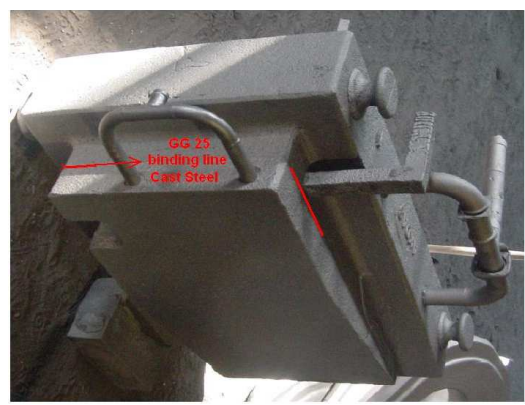

Fig. 1. View of vasting part.

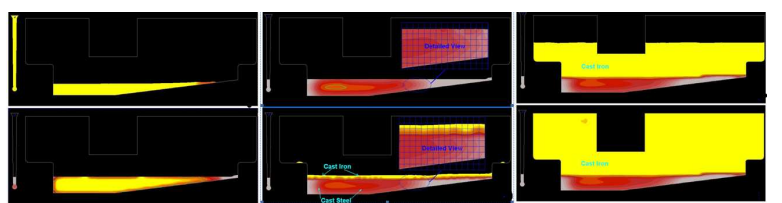

Fig. 2. Computer simulation studies.

holes, and distortion etc. has not taken place during solidification and has not been observed along the interface.

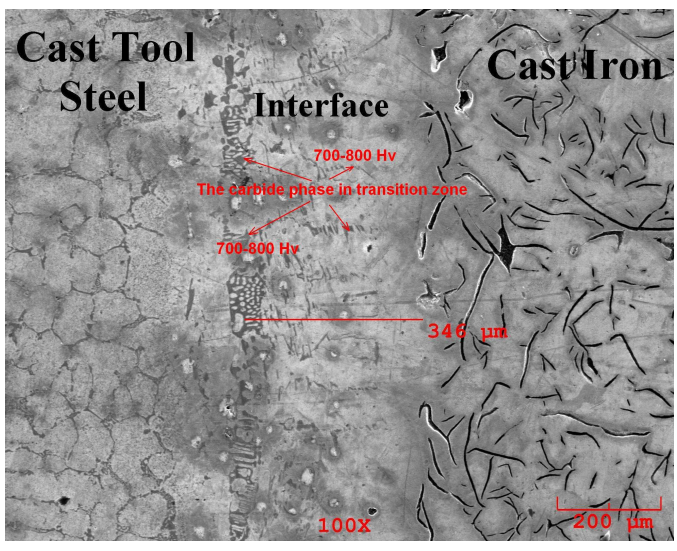

Fig. 3. SEM micrographs of the cross-section for interface zone of as cast bimetal.

Vickers microhardness values were measured across the interaction area and the microhardness profile was drawn from the cast steel to the gray iron seen in Fig. 4. Some microhardness of interaction areas has higher hardness than both that of the cast tool steel and that of the gray iron since the diffusion of alloying elements causes the formation of new interphases and carbides in the interaction area.

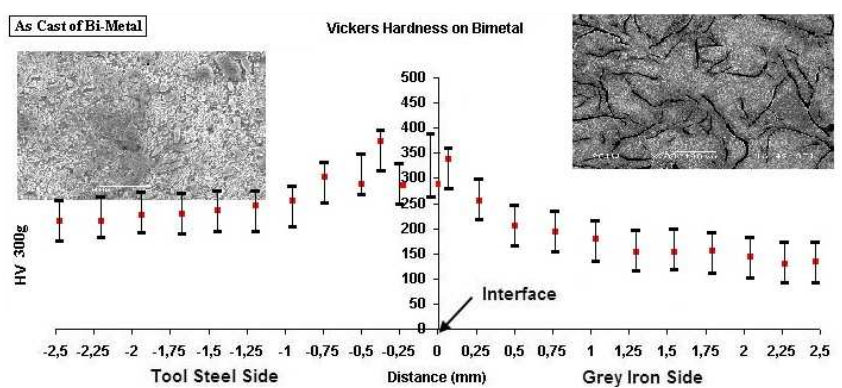

Fig. 4. Profile of hardness of the interface layer of bimetal.

\section{Conclusions}

At various press dies, which are made from cast tool steel, the benefits bimetal castings are obvious. The cutting edge demands the hardness whereas the base material remains tough and ductile. The microhardness of the treated layer on the cast tool steel substrate is about 600-750 Hv, while the hardness of the substrate is about $250 \mathrm{Hv}$.

\section{Acknowledgments}

The authors would like to thank Mr. Hasan Dağlı (GSA Mühendislik), Mr. Orhan Çakır (Akdaş Casting Ind. \& Trade Co.) and Novacast-Camito Techonologies AB.

\section{References}

[1] Xiuling Su, Ph.D. thesis, University of Cincinnati, 2001.

[2] Xinyu Zhou, Ph.D. thesis, University of Cincinnati, 2005.

[3] L. Guobin, W. Jianjun, L. Xiangzhi, L. Guiyun, J. Mater. Proc. Technol. 75, 152 (1998).

[4] L. Mehnen, H. Pfutzner, E. Kaniusas, J. Magn Magn. Mater. 215-216, 779 (2000).

[5] J. Nakano, Y. Miwa, T. Tsukada, M. Kikuchi, S. Kita, Y. Nemoto, H. Tsuji, S. Jitsukawa, J. Nucl. Mater. 307, 1568 (2002).

[6] K.V. Sudakhar, Eng. Failure Anal. 9, 221 (2002).

[7] O. Yilmaz, H. Çelik, J. Mater. Proc. Technol. 141, 67 (2003).

[8] B.V. Krishna, P. Venugopal, K.P. Rao, Mater. Sci. Eng. A 407, 77 (2005).

[9] U. Patel, S. Suresh, J. Colloid Interface Sci. 299 249 (2006).

[10] D.C. Ko, S.K. Lee, B.M. Kim, H.H. Jo, H. Jo, J. Mater. Process. Technol. 186, 22 (2007).

[11] M. Şimşir, L.C. Kumruoğlu, A. Özer, Mater. Des. 30, 264 (2009). 